\title{
Deactivation Behavior of Supported Gold Palladium Nanoalloy Catalysts during the Selective Oxidation of Benzyl Alcohol in a Micropacked Bed Reactor
}

\author{
Noor Al-Rifai, ${ }^{\dagger, \perp}$ Peter J. Miedziak, ${ }^{\ddagger}$ Moataz Morad, ${ }^{\ddagger}$, Meenakshisundaram Sankar, $^{\ddagger}$ Conor Waldron,
} Stefano Cattaneo, ${ }^{\ddagger}$ Enhong Cao, ${ }^{\dagger}$ Samuel Pattisson, ${ }^{\ddagger}$ David Morgan, ${ }^{\ddagger}$ Donald Bethell, ${ }^{\|}$ Graham J. Hutchings, ${ }^{\dagger}$ and Asterios Gavriilidis*, ${ }^{*}+0$

${ }^{\dagger}$ Department of Chemical Engineering, University College London, Torrington Place, London WC1E 7JE, U.K.

${ }^{\ddagger}$ Cardiff Catalysis Institute, School of Chemistry, Cardiff University, Cardiff, CF10 3AT, U.K.

${ }^{\S}$ Chemistry Department, Faculty of Science, Umm Al-Qura University, PO. Box 21955, 9264 Makkah, Saudi Arabia

"Department of Chemistry, University of Liverpool, Crown Street, Liverpool, L69 7ZD, U.K.

${ }^{\perp}$ Coty Inc., Luxury Fragrances R\&D, Product Development, HFC Prestige, Egham, TW20 9NW, U.K.

Supporting Information

ABSTRACT: Highly active, supported Au-Pd catalysts have been tested for catalyzing benzyl alcohol oxidation in a siliconglass micropacked bed reactor. The effects of $\mathrm{Au}-\mathrm{Pd}$ composition and anion content during catalyst preparation on catalyst deactivation were studied, and a relationship between the deactivation rate and the amount of $\mathrm{Cl}^{-}$and $\mathrm{Au}$ used in the catalyst formulation was found. While $\mathrm{Au}$ aids in enhancing the selectivity to the desired product and the $\mathrm{Cl}^{-}$ions help the formation of uniform 1-2 nm nanoparticles, higher amounts of $\mathrm{Au}$ and $\mathrm{Cl}^{-}$become detrimental to the catalyst stability once a certain amount is exceeded. Loss of small (1-2 nm) metal nanoparticles was evident in all catalysts studied, accompanied by agglomeration and the formation of larger $>10 \mathrm{~nm}$ particles. A secondary deactivation mechanism characterized by the formation of an amorphous surface film was observed via transmission electron microscopy in catalysts with high $\mathrm{Cl}^{-}$ and $\mathrm{Au}$ and was associated with the detection of carbon species on the catalyst surface using Raman spectroscopy.

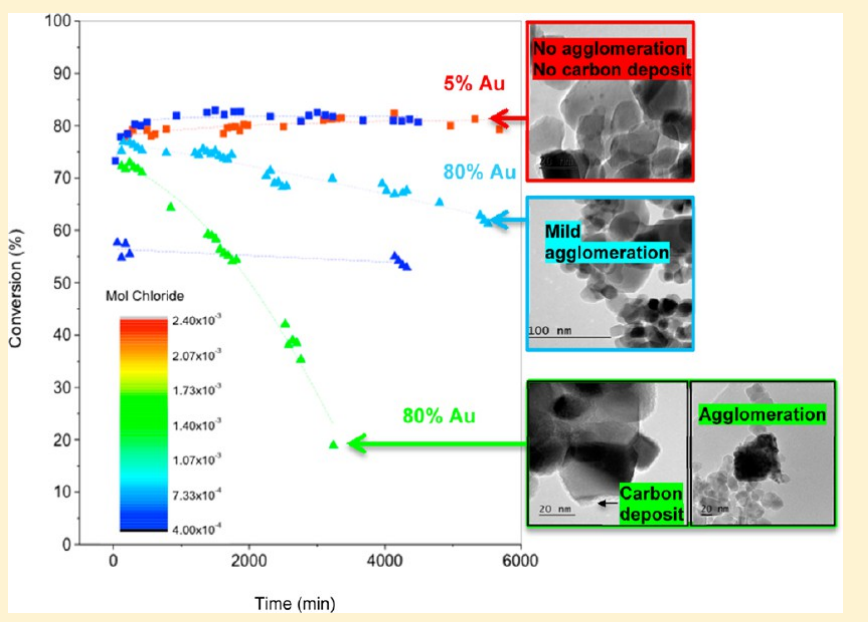

Trade-offs exist between complexity of preparation method and the catalytic activity of the resulting catalyst. The simplest method of preparing $\mathrm{Au}-\mathrm{Pd}$ nanoalloy catalysts is conventional impregnation, however, this method produces nanoparticles with a wide particle size distribution ranging from 1 to $10 \mathrm{~nm}$, together with large $>10 \mathrm{~nm}$ particles. Catalysts prepared by solimmobilization - a method that uses stabilizer ligands to control the particle size and avoid the formation of catalytically inactive larger particles-were found to have high catalytic activity, but the disadvantage of being unstable. ${ }^{5}$ Recent studies on the use of an excess anion modified impregnation $\left(\mathrm{M}_{\mathrm{Im}}\right)$ method in the

Special Issue: Tapio Salmi Festschrift

Received: March 20, 2017

Revised: $\quad$ May 19, 2017

Accepted: May 26, 2017

Published: May 26, 2017 
preparation of supported gold-palladium catalysts have shown that through the addition of excess chloride ions to the metal precursors during the impregnation stage, a catalyst that possesses a very tight particle size distribution can be produced. ${ }^{6,7}$ The improvement in activity is postulated to be due to the combination of particle size control, elimination of size-dependent compositional variation, and the random alloy nanostructure. ${ }^{6}$

One of the major challenges in commercializing promising catalysts is ensuring stability under industrially relevant conditions. ${ }^{8}$ Typically, the stability of these catalysts is studied in a batch reactor using a "recover and re-use" strategy, a procedure that is not representative of typical industrial operations. A more effective method for testing the catalyst stability is through the use of a flow reactor, with which the stability of the catalyst can be monitored with time on stream. The small inventories of catalyst and reactants required in microreactors gives them a competitive edge as laboratory tools for this kind of studies. Rapid manipulation of reaction conditions, fast response times, and precise control over the hydrodynamic environment have increased their use in reaction kinetic studies, in situ spectroscopic characterization, and reaction optimization, making them ideal candidates for testing of catalytic stability. ${ }^{9}$

The deactivation of solid catalysts in the liquid phase reactions is usually caused by physical, thermal, or chemical changes of the catalyst. ${ }^{10}$ Four main modes of deactivation have been identified in Pt-group metal catalyzed reactions: (1) change of oxidation state of the active metal site ("over-oxidation"), (2) irreversible adsorption of products or polymeric species, and (3) loss of metal surface area by leaching or (4) sintering. ${ }^{11,12}$ The inhibitory effect of chlorine when used in a metal precursor has been investigated by others, but primarily for gas phase reactions. ${ }^{13,14}$ Peri et al. ${ }^{13}$ raised the possibility that the activation phenomenon (the increase in catalytic activity with time on stream at start-up) in catalysts prepared from chlorinated precursors, could be due to the slow removal of chlorine with time. The negative effect of residual chlorine on the catalyst has been attributed to several causes, including partial blockage of metal particles by chlorine ${ }^{15}$ and the generation of metal oxychloride species that have higher reduction temperatures and lead to a less active oxidation site. ${ }^{16}$ A mechanism for the mobility of chloride ions during reduction and reaction has been presented elsewhere; ${ }^{15}$ the reduction of the catalyst has been postulated to cause mobility of the chloride ions from the surface of the metal particles to the interior of the particles and on the support. The introduction of the oxidant is then hypothesized to cause movement of the chlorine to the metal particle surface again. The use of $\mathrm{H}_{2}+\mathrm{H}_{2} \mathrm{O}$ treatment has been shown to favor the definitive chlorine elimination from the catalyst (i.e., $\mathrm{H}_{2} \mathrm{O}$ reacts with the $\mathrm{Cl}$ to produce $\mathrm{HCl}$ ).

The objective of this work is to investigate the stability of supported $1 \% \mathrm{AuPd} / \mathrm{TiO}_{2}$ catalysts prepared by impregnation methodologies during the aerobic selective oxidation of benzyl alcohol in a micropacked bed reactor. Three catalyst preparation methods are investigated: conventional impregnation and two types of modified impregnation methods, where an excess of anion (chloride ions) during the wet impregnation stage is used. The influence of $\mathrm{Au}$ and $\mathrm{Cl}^{-}$ion contents on catalyst stability is studied, and a possible deactivation mechanism is presented, aided by the following characterization techniques: scanning electron microscopy (SEM), transmission electron microscopy (TEM), X-ray photoelectron spectroscopy (XPS), atomic emission spectroscopy (AES), and Raman spectroscopy.
1.1. Benzyl Alcohol Oxidation on Supported Au-Pd Catalysts. A generalized reaction scheme for the oxidation of benzyl alcohol on $\mathrm{Au}-\mathrm{Pd}$ catalysts is presented in Figure 1. In the

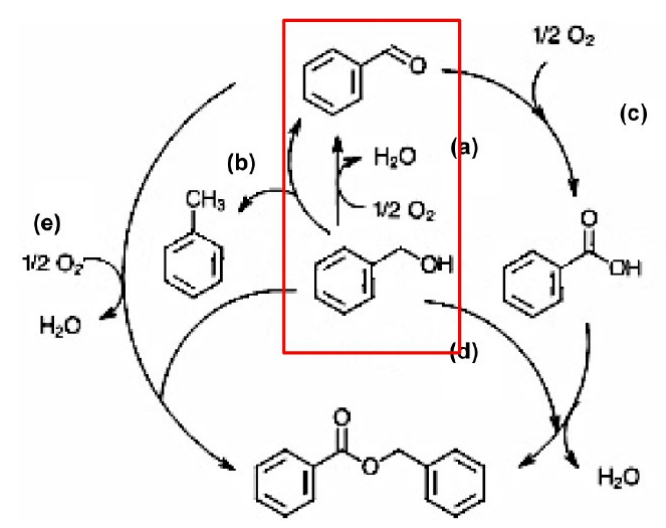

Figure 1. Benzyl alcohol oxidation reaction network: (a) oxidation of benzyl alcohol to benzaldehyde; (b) disproportionation of benzyl alcohol to benzaldehyde and toluene; (c) oxidation of benzaldehyde to benzoic acid; (d) esterification of benzyl alcohol and benzoic acid; (e) esterification of benzyl alcohol and benzaldehyde under oxidative conditions to benzyl benzoate. The main reaction is highlighted in the red box.

presence of oxygen, the oxidation of benzyl alcohol leads in the first instance to the formation of benzaldehyde, which further oxidizes to benzoic acid. ${ }^{17}$ The formation of benzyl benzoate is through an esterification reaction between the initial alcohol and the (i) generated aldehyde (in the presence of oxygen) or (ii) the generated benzoic acid. ${ }^{18}$ Typically, benzoic acid, benzyl benzoate, and dibenzyl ether are produced in much smaller quantities $(<5 \%)$ compared to benzaldehyde and toluene. ${ }^{19}$ Disproportionation of two moles of benzyl alcohol leads to an equimolar mixture of toluene and benzaldehyde. The use of $\mathrm{Au}-\mathrm{Pd}$ catalyst similar to the one used in this study, for catalyzing benzyl alcohol oxidation among other alcohols, has been demonstrated in previous studies. ${ }^{20-23}$ However, the deactivation of this particular catalyst prepared via the modified impregnation technique under flow conditions has not been studied yet.

\section{MATERIALS AND METHODS}

2.1. Catalyst Preparation Methods. Two main catalyst preparation methods are used in this study: conventional impregnation $\left(\mathrm{C}_{\mathrm{Im}}\right)$ and modified impregnation $\left(\mathrm{M}_{\mathrm{Im}}\right)$. Within the modified impregnation category, there exists two types: modified impregnation constant $\mathrm{Cl}\left(\mathrm{M}_{\mathrm{Im}, \mathrm{const}}\right)$ and modified impregnation varying $\mathrm{Cl}\left(\mathrm{M}_{\mathrm{Im}, \mathrm{vary}}\right)$. The catalyst preparation methods for each of these catalysts will be presented next.

2.1.1. Conventional Impregnation, $C_{I m}$. The conventional impregnation $\left(\mathrm{C}_{\mathrm{Im}}\right)$ preparation procedure for supported $\mathrm{Au}-\mathrm{Pd}$ catalysts relies on a wet-impregnation method, which has been reported in previous articles. ${ }^{4}$ In a typical synthesis, an aqueous mixture of the metal precursors $\mathrm{PdCl}_{2}$ and $\mathrm{HAuCl}_{4} \cdot 3 \mathrm{H}_{2} \mathrm{O}$ (Sigma-Aldrich) are wet impregnated on to the solid support $\mathrm{TiO}_{2}$ (Evonik P25). This is done by adding the requisite amount of solid $\mathrm{PdCl}_{2}$ to a predetermined volume of an aqueous solution of $\mathrm{HAuCl}_{4} \cdot 3 \mathrm{H}_{2} \mathrm{O}$ and stirring vigorously at $80{ }^{\circ} \mathrm{C}$ for a few minutes, until the palladium salt apparently dissolves. The requisite amount of the support is then added to this solution under vigorous stirring conditions until it forms a paste, which is 
Conventional

Impregnation $\mathbf{C}_{\mathrm{Im}}$

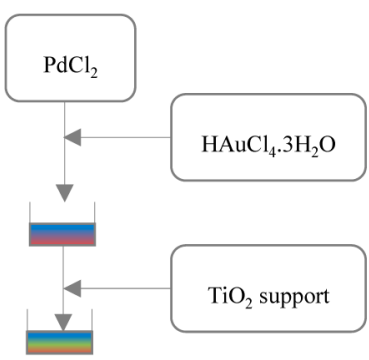

Modified Impregnation

Varying $\mathrm{Cl}^{-} \mathrm{M}_{\mathrm{Im}, \mathrm{vary}}$

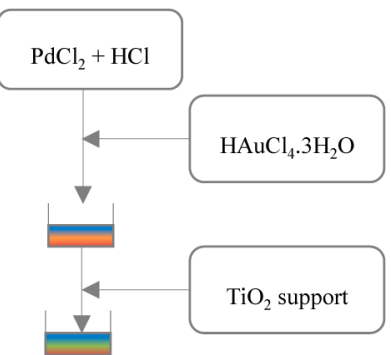

Modified Impregnation

Constant $\mathrm{Cl}^{-} \mathrm{M}_{\text {Im,const }}$

Figure 2. Steps for the preparation of catalysts via three methods: conventional impregnation, modified impregnation varying $\mathrm{Cl}^{-}$, and modified impregnation constant $\mathrm{Cl}^{-}$.

Table 1. Preparation Methods and Loading of $\mathrm{Au}-\mathrm{Pd} / \mathrm{TiO}_{2}$ Catalysts Studied in This Work

\begin{tabular}{|c|c|c|c|c|c|}
\hline abbreviation & preparation method & Au wt $\%$ & Pd wt \% & $\mathrm{mol} \mathrm{Cl}^{-a}$ & $\mathrm{Cl}^{-}: \mathrm{Pd}$ mol ratio ${ }^{b}$ \\
\hline $\mathrm{C}_{\mathrm{Im}} 80-20$ & conventional impregnation & 0.8 & 0.2 & $4 \times 10^{-4}$ & 10.6 \\
\hline$M_{\text {Im }} 65-35$ & modified impregnation varying $\mathrm{Cl}^{-}$ & 0.65 & 0.35 & $1.07 \times 10^{-3}$ & 20.6 \\
\hline $\mathrm{M}_{\mathrm{Im}} 80-20 \mathrm{HEC}$ & modified impregnation constant $\mathrm{Cl}^{-}$ & 0.8 & 0.2 & $1.37 \times 10^{-3}$ & 36.1 \\
\hline $\mathrm{M}_{\mathrm{Im}} 80-20 \mathrm{LEC}$ & modified impregnation varying $\mathrm{Cl}^{-}$ & 0.8 & 0.2 & $7.87 \times 10^{-4}$ & 20.9 \\
\hline $\mathrm{M}_{\mathrm{Im}}$ 5-95 LAu & modified impregnation varying $\mathrm{Cl}^{-}$ & 0.05 & 0.95 & $2.22 \times 10^{-3}$ & 12.4 \\
\hline
\end{tabular}

${ }^{a_{T}}$ This includes the $\mathrm{Cl}^{-}$from the metal precursors $\left(4 \times 10^{-4}\right.$ moles for $2 \mathrm{~g}$ of catalyst $)$ and any excess $\mathrm{Cl}^{-}$. $\mathrm{C}_{\mathrm{Im}}$ will contain $\mathrm{Cl}^{-}$only from the precursors. ${ }^{b} \mathrm{Cl}^{-}$based on calculated amount added during preparation.

then dried at $120^{\circ} \mathrm{C}$ for $16 \mathrm{~h}$ and reduced in a stream of $5 \% \mathrm{H}_{2}$ in Ar at $400{ }^{\circ} \mathrm{C}$ for $4 \mathrm{~h}$.

2.1.2. Modified Impregnation, $M_{I m}$. In the modified impregnation $\mathrm{M}_{\mathrm{Im}}$ procedure, an excess of $\mathrm{Cl}^{-}$(dilute $\mathrm{HCl}$ ) is added to the formulation; this is done in one of two ways (Figure 2):

(1) Solid $\mathrm{PdCl}_{2}$ is dissolved in $0.58 \mathrm{M} \mathrm{HCl}$ to form a $\mathrm{Pd}$ precursor solution (concentration $6 \mathrm{mg} \mathrm{Pd} / \mathrm{mL}$ ) and it is added to an aqueous solution of $\mathrm{Au}\left(\mathrm{HAuCl}_{4} \cdot 3 \mathrm{H}_{2} \mathrm{O}\right.$ dissolved in water with a $\mathrm{Au}$ concentration of $8.9 \mathrm{mg}$ $\mathrm{Au} / \mathrm{ml})$. The amount of precursor solution taken for the synthesis depends on the required ratio of $\mathrm{Au}$ and $\mathrm{Pd}$ in the final catalyst $\left(\mathbf{M}_{\mathrm{Im} \text {,vary }}\right.$ : the amount of $\mathrm{Cl}$ varies with $\mathrm{Pd}$ loading);

(2) Requisite amounts of solid $\mathrm{PdCl}_{2}$ and Au precursor solution $\left(\mathrm{HAuCl}_{4} \cdot 3 \mathrm{H}_{2} \mathrm{O}\right.$ dissolved in water with a $\mathrm{Au}$ concentration of $8.9 \mathrm{mg} \mathrm{Au} / \mathrm{mL}$ ) in a fixed amount of $\mathrm{HCl}$ (chloride amount in the solution $=9.7 \times 10^{-4} \mathrm{~mol}$ ) are used as precursors for this methodology $\left(\mathbf{M}_{\mathrm{Im}, \text { const }}\right.$ : the amount of $\mathrm{Cl}$ is constant with $\mathrm{Pd}$ loading).

The precursor solutions are mixed thoroughly in a $50 \mathrm{~mL}$ round-bottom flask in a hot plate and stirred vigorously at $1000 \mathrm{rpm}$ using a magnetic stirrer bar, while slowly raising the temperature from 27 to $60{ }^{\circ} \mathrm{C}$. The metal oxide support material $\mathrm{TiO}_{2}$ (Degussa P25) is then added over a period of 8 to $10 \mathrm{~min}$ with constant stirring. The formed slurry is stirred at $60{ }^{\circ} \mathrm{C}$ for $15 \mathrm{~min}$ and the temperature of the oil bath is raised to $95^{\circ} \mathrm{C}$. The slurry is stirred at that temperature for a further $16 \mathrm{~h}$ until all the water evaporates, leaving a dry solid. This dry powder is then transferred to a mortar and pestle and ground thoroughly to form a uniform mixture. The resulting powder is reduced $400{ }^{\circ} \mathrm{C}$ under a steady flow of $5 \% \mathrm{H}_{2}$ in $\mathrm{Ar}$ for $4 \mathrm{~h}$ in a furnace. A summary of the catalysts used in the study is shown in Table 1, and a schematic of the preparation steps is shown in Figure 2 .
2.2. Catalyst Analysis. 2.2.1. Scanning Electron Microscopy (SEM). A JEOL 7401 high-resolution field emission scanning electron microscope was used to image the fresh catalyst. The backscattered electrons (BSE) were analyzed to illustrate the contrast between $\mathrm{TiO}_{2}$ and the $\mathrm{Au}-\mathrm{Pd}$ particles in order to get an initial estimation of the particle size and the location of metal particles.

2.2.2. TEM Imaging. TEM was carried out using a JEOL 2100 with a $\mathrm{LaB}_{6}$ filament operating at $200 \mathrm{kV}$. Samples were prepared by dispersing the powder catalyst in ethanol and dropping the suspension onto a lacey carbon film over a 300 mesh copper grid.

2.2.3. High Resolution-Scanning Transmission Electron Microscopy (HR-STEM) and Energy Dispersive X-ray Spectroscopy (EDS). A JEOL 1010 Transmission Electron microscope was used to carry out HR-STEM with EDS to identify the Au and Pd metal on the support. The samples were prepared for TEM by placing a droplet of the powder material dispersed in ethanol (sonicated for $5 \mathrm{~min}$ in an ultrasonic bath) on a carbon-coatedmesh grid.

2.2.4. X-ray Photoelectron Spectroscopy (XPS). Samples were characterized using a Kratos Axis Ultra-DLD photoelectron spectrometer, using monochromatic $\mathrm{Al} \mathrm{K} \alpha$ radiation, at $144 \mathrm{~W}$ $(12 \mathrm{~mA} \times 12 \mathrm{kV})$ power. High resolution and survey scans were performed at pass energies of 40 and $160 \mathrm{eV}$, respectively. Spectra were calibrated to the C (1s) signal for adventitious carbon at $284.78 \mathrm{eV}$ and quantified using CasaXPS v2.3.1517, utilizing sensitivity factors supplied by the manufacturer.

2.2.5. Atomic Emission Spectroscopy (AES). An Agilent MP-AES 4100 was used to detect metal leaching into the reaction solution. Samples were tested for gold and palladium using a gold wavelength of $242.795 \mathrm{~nm}$ and palladium wavelength of $363.470 \mathrm{~nm}$. The samples were diluted in 2:1 propanol to benzyl alcohol. Three repeats of each sample were conducted. Standards $(1,5$, and $10 \mathrm{ppm}$ for $\mathrm{Au}$ and $\mathrm{Pd})$ and blanks were made in 2:1 propanol to benzyl alcohol for matrix mapping of solutions. 
2.2.6. Raman Spectroscopy. Raman measurements were carried out using a Renishaw inVia Raman spectrometer coupled to a Leica microscope. Spectra were excited using the $514.5 \mathrm{~nm}$ line from a LaserPhysics argon ion laser. Raman scattered light was detected using a CCD detector. Spectra were recorded with an integration time of $10 \mathrm{~s}$ and averaged once. The catalyst was imaged while in the microreactor.

2.2.7. Continuous Flow Microfluidic Experimental System. 2.2.7.1. Microstructured Reactor Design. The microreactors were fabricated by photolithography and deep reactive ion etching as described in ref 19. A serpentine microchannel reactor with channel dimensions of $600 \mu \mathrm{m}(\mathrm{W}) \times 300 \mu \mathrm{m}(\mathrm{H}) \times$ $190 \mathrm{~mm}$ (L) was used (only a portion of the total channel length is used for reaction). The gas was introduced into the liquid flow path via a T-junction, and the gas-liquid mixture traveled down the serpentine channel in slug flow before reaching the catalytic bed. At the end of the microchannel, $60 \mu$ m width retention posts with $40 \mu \mathrm{m}$ gaps were used to retain the catalyst.

2.2.7.2. Catalyst Pelletization and Loading. The powder catalyst was first pelletized using a pellet press. The powder was compressed to $40 \mathrm{kN}$ in a die with a diameter of $10 \mathrm{~mm}$. The pellet was then crushed using a mortar and pestle and sieved. Four milligrams of the sieved catalyst granules $(50-60 \mu \mathrm{m})$ were loaded into the microreactor by applying a vacuum to the outlet port. Glass beads $60-70 \mu \mathrm{m}$ in particle size were placed before the catalytic bed (to stabilize the flow before entering the bed) and after the catalytic bed (as a secondary precaution to prevent catalyst leaving the reactor). The length of glass beads was $3 \mathrm{~mm}$ preceding and $1 \mathrm{~mm}$ succeeding the catalytic bed.

2.2.7.3. Flow Setup. Continuous flow experiments were performed at $120^{\circ} \mathrm{C}$ and pressures ranging between 0 and 1 barg using a dual microreactor experimental set up. A Harvard syringe pump (PhD Ultra, Harvard Apparatus) equipped with $2 \times 2.5 \mathrm{~mL}$ syringes was used to deliver $3 \mu \mathrm{L} / \mathrm{min}$ liquid alcohol (benzyl alcohol 99.98\%, Sigma-Aldrich) to the reactors in a semicontinuous mode (due to the limitation of the syringe volumes which required refilling every $\sim 13 \mathrm{~h}$ ). Two mass flow controllers (Brooks 5850TR, Brooks Instruments) were used to deliver $0.6 \mathrm{~N} \mathrm{~mL} / \mathrm{min}$ of oxygen gas (N5.5 grade, BOC) to each reactor, and a pressure gauge (SS BP Regulator, Swagelok) upstream of each reactor was used to monitor the pressure.

The effluent from the reactor flowed into a $2 \mathrm{~mL}$ glass vial located in a cold trap (iced beaker), where gas and liquid were separated and the liquid product collected for analysis. The reactor temperature was controlled to $120{ }^{\circ} \mathrm{C}$ using a hot plate regulated by a temperature controller (Watlow CAL 9900, Watlow Ltd.). Thermocouples (TJC Series, Omega Engineering Ltd.), $0.25 \mathrm{~mm}$ in diameter, were inserted on-chip to regulate the temperature at the microreactor surface. The pressure in the microreactor was near atmospheric and was dictated by the pressure drop across the bed. The pressure drop ranged between $0.2-0.6$ bar.

Quantitative analysis was carried out on the liquid samples using a gas chromatograph (Agilent 6890, Agilent Technologies) with an FID detector, a HP-INNOWax (19091- 133) capillary column and an autoliquid-sampler. For the analysis, $10 \mu \mathrm{L}$ of the collected sample was diluted with $0.5 \mathrm{~mL}$ of $3 \%(\mathrm{v} / \mathrm{v})$ butanol in $o$-xylene as an external standard.

\section{RESULTS AND DISCUSSION}

3.1. Effect of Preparation Method on Catalytic Activity. All $\mathrm{M}_{\text {Im }}$ catalysts had similar initial activities, with initial conversions of $\sim 80 \%$ (Figure 3 ). The activities of $\mathrm{M}_{\mathrm{Im}}$ catalysts

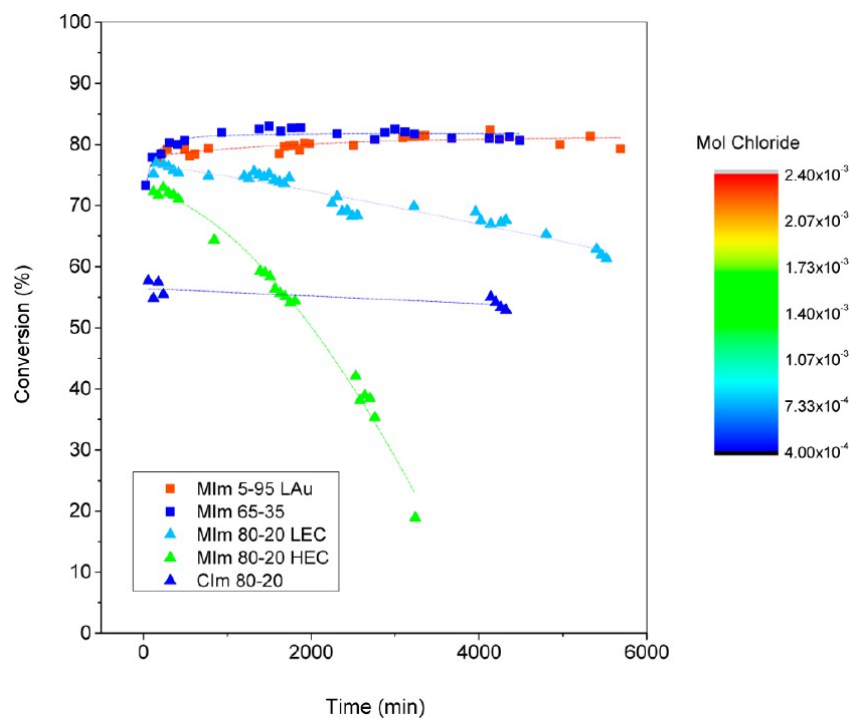

Figure 3. Deactivation profiles of $\mathrm{M}_{\mathrm{Im}}$ and $\mathrm{C}_{\mathrm{Im}}$ catalysts of differing chloride ion and $\mathrm{Au}: \mathrm{Pd}$ ratios. $\mathrm{Mol} \mathrm{Cl}^{-}$reported is the amount used in the catalyst preparation.

were considerably higher than the $\mathrm{C}_{\mathrm{Im}}$ catalyst possessing the same formulation. The superior performance of $M_{I m}$ catalysts is due to the improved control over the particle size, elimination of size-dependent compositional variation and random alloy nanostructure, as discussed previously. The selectivity to the main products (benzaldehyde and toluene) was unaffected by the catalyst preparation method and averaged at around $60 \%$ and $40 \%$ for benzaldehyde and toluene, respectively (see Figure S1 in the Supporting Information).

3.2. Effect of $\mathrm{Au}$ and $\mathrm{Cl}^{-}$on Catalyst Stability. The stability of $\mathrm{M}_{\mathrm{Im}}$ catalysts varied depending on the amount of $\mathrm{Au}$ and $\mathrm{Cl}^{-}$used in the catalyst preparation. Figure 4 displays a comparison of the extent of deactivation over a period of $50 \mathrm{~h}$, as a function of mole of chloride, grouping together catalysts with the same $\mathrm{Au}-\mathrm{Pd}$ ratio. Within the same catalyst formulation, 80-20 Au-Pd, there is an exponential relationship between the

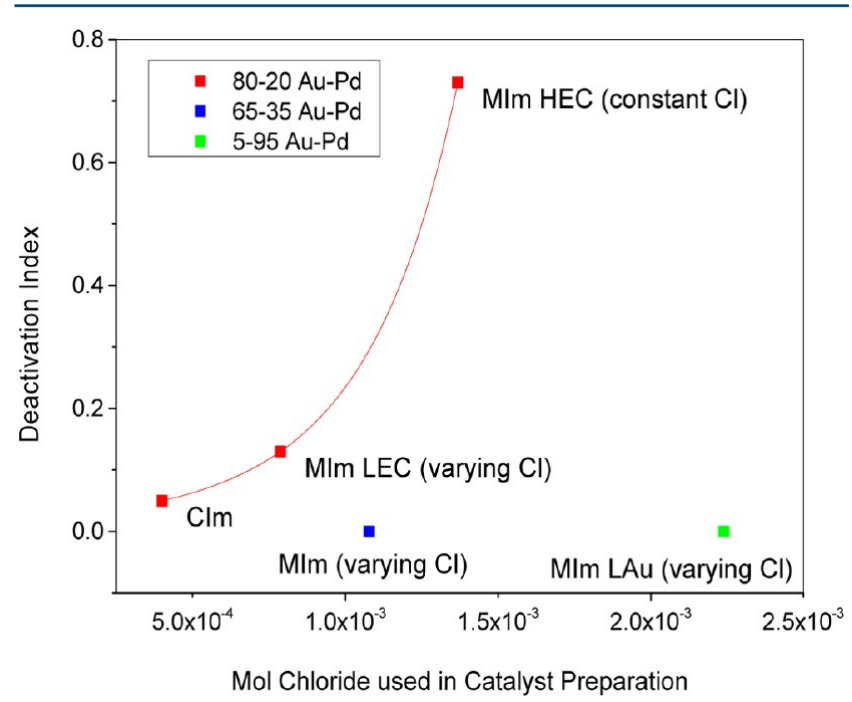

Figure 4. Deactivation index $\left[\frac{X_{\mathrm{o}}-X_{\mathrm{f}}}{X_{\mathrm{o}}}\right]$ (extent of deactivation) as a function of amount of chloride in the formulation, where $X_{\mathrm{o}}$ is initial conversion and $X_{\mathrm{f}}$ is conversion after $50 \mathrm{~h}$. 
Table 2. XPS of Fresh and Used $M_{I m}$ HEC 80-20 Au-Pd

\begin{tabular}{|c|c|c|c|c|c|c|c|}
\hline & \multicolumn{5}{|c|}{ XPS derived molar concentration (atom \%) } & \multicolumn{2}{|c|}{ metal binding energy $(\mathrm{eV})$} \\
\hline & $\mathrm{Pd}$ & $\mathrm{Au}$ & $\mathrm{O}$ & $\mathrm{Ti}$ & $\mathrm{C}$ & $\operatorname{Pd}\left(3 d_{5 / 2}\right)$ & $\operatorname{Au}\left(4 f_{7 / 2}\right)$ \\
\hline fresh & 0.07 & 0.03 & 35.32 & 14.73 & 49.84 & 334.8 & 83.3 \\
\hline used & 0.08 & 0.03 & 36.46 & 13.53 & 49.90 & 334.8 & 83.3 \\
\hline
\end{tabular}
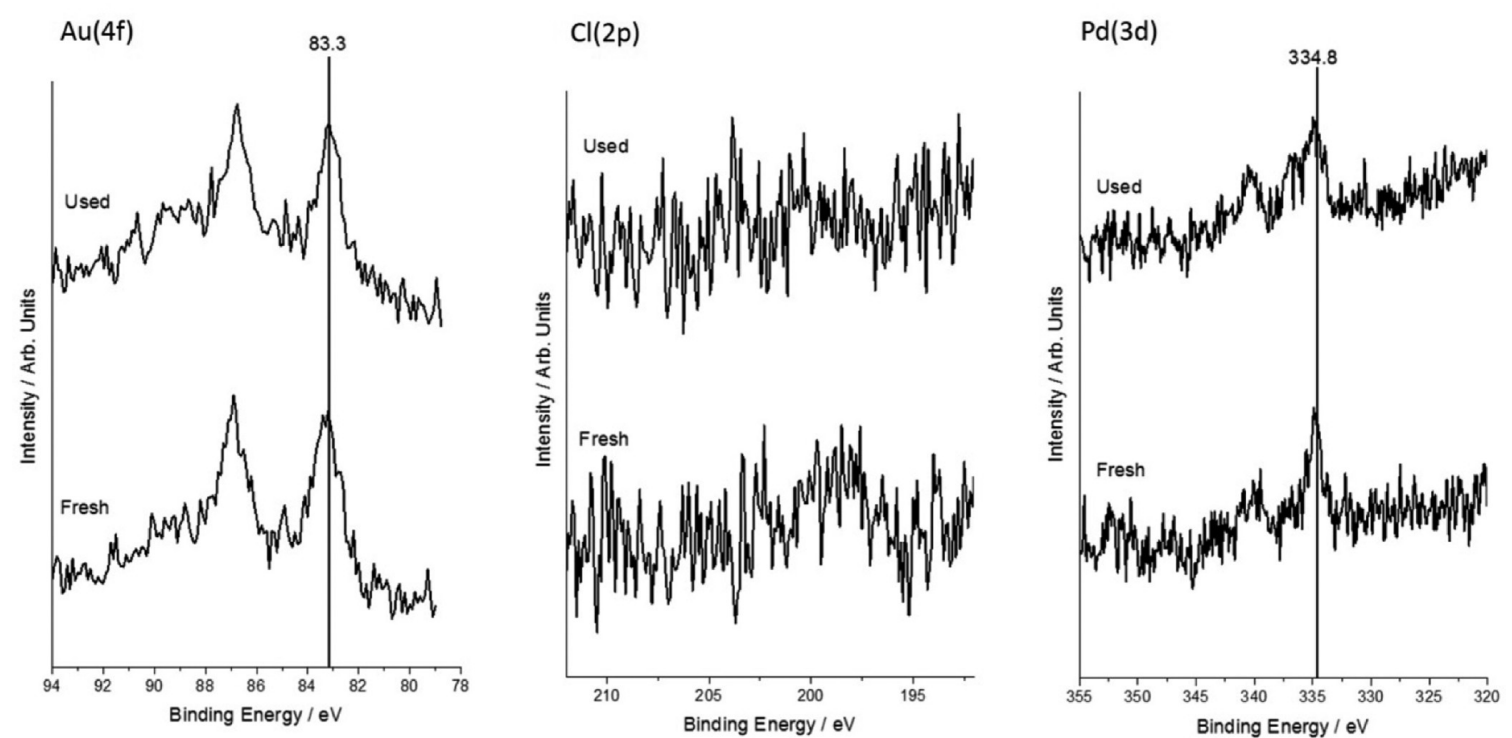

Figure 5. XPS spectra of fresh and used $\mathrm{M}_{\mathrm{Im}}$ HEC 80-20 Au-Pd.
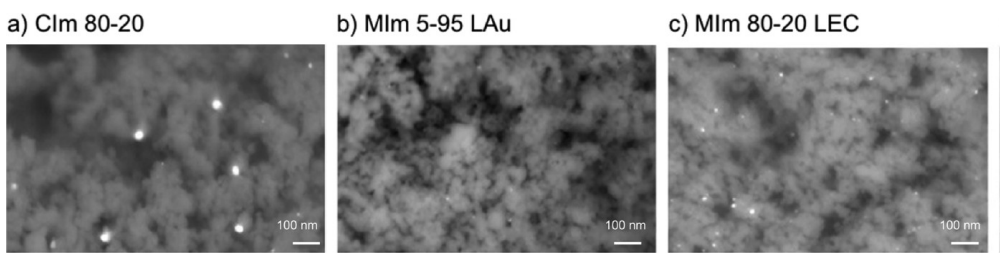

d) MIm 80-20 HEC

Figure 6. BSE-SEM images of fresh $\mathrm{C}_{\mathrm{Im}}$ and $\mathrm{M}_{\mathrm{Im}}$ catalysts.
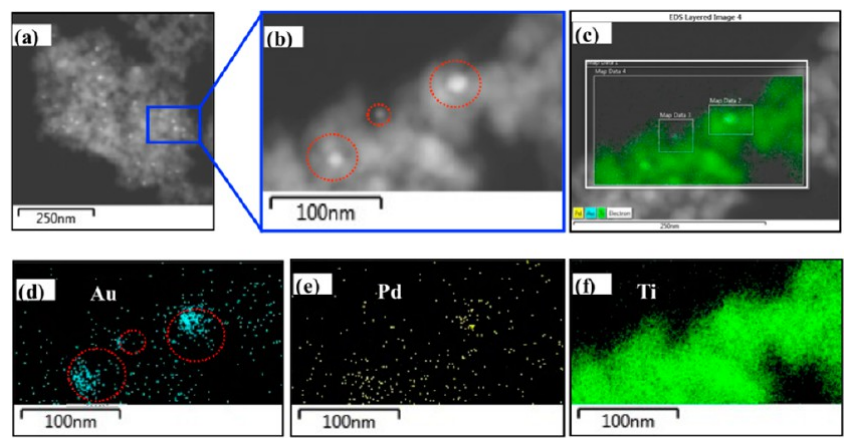

Figure 7. (a) HR-STEM EDS of $\mathrm{M}_{\mathrm{Im}}$ HEC 80-20 Au-Pd, (b) electron images showing metal clusters highlighted with red circles, (c) the entire mapped area, (d) mapped Au signal, (e) mapped Pd signal, and (f) mapped titanium signal.

$\mathrm{Cl}^{-}$amount and the deactivation rate. The $\mathrm{M}_{\text {Im }}$ HEC 80-20 $\mathrm{Au}-\mathrm{Pd}$ catalyst with $1.37 \times 10^{-3}$ moles of $\mathrm{Cl}^{-}$deactivated by $75 \%$ over $50 \mathrm{~h}$. In contrast, $13 \%$ deactivation was observed with the $\mathrm{M}_{\mathrm{Im}} \mathrm{LEC} 80-20 \mathrm{Au}-\mathrm{Pd}$ catalyst, which had lower moles of $\mathrm{Cl}^{-}$used in its preparation $\left(7.87 \times 10^{-4} \mathrm{~mol}\right)$. Little deactivation was observed with the $\mathrm{C}_{\mathrm{Im}} 80-20 \mathrm{Au}-\mathrm{Pd}$ catalyst, which had $4.00 \times 10^{-4}$ moles of $\mathrm{Cl}^{-}$used in its preparation. In contrast, low Au formulations showed good stability, despite the high
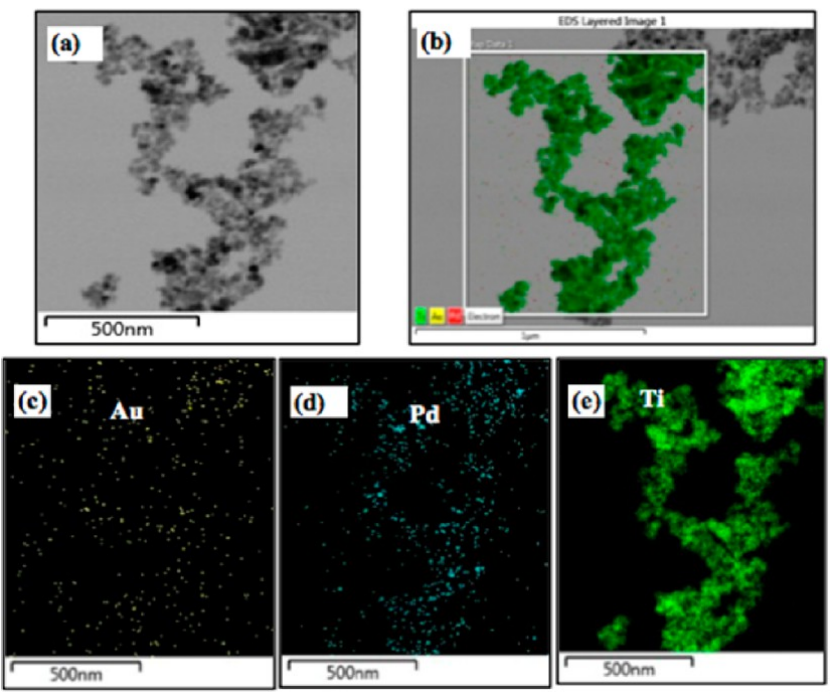

Figure 8. HR-STEM EDS $\mathrm{M}_{\mathrm{Im}}$ 5-95 LAu (a) electron image, (b) the mapped area, (c) mapped Au signal, (d) mapped Pd signal, and (e) mapped titanium signal.

$\mathrm{Cl}^{-}$used in their preparation; the 5-95 Au-Pd with a higher $\mathrm{Cl}^{-}$ content than the $\mathrm{M}_{\mathrm{Im}}$ HEC $80-20\left(2.22 \times 10^{-3}\right.$ compared to 


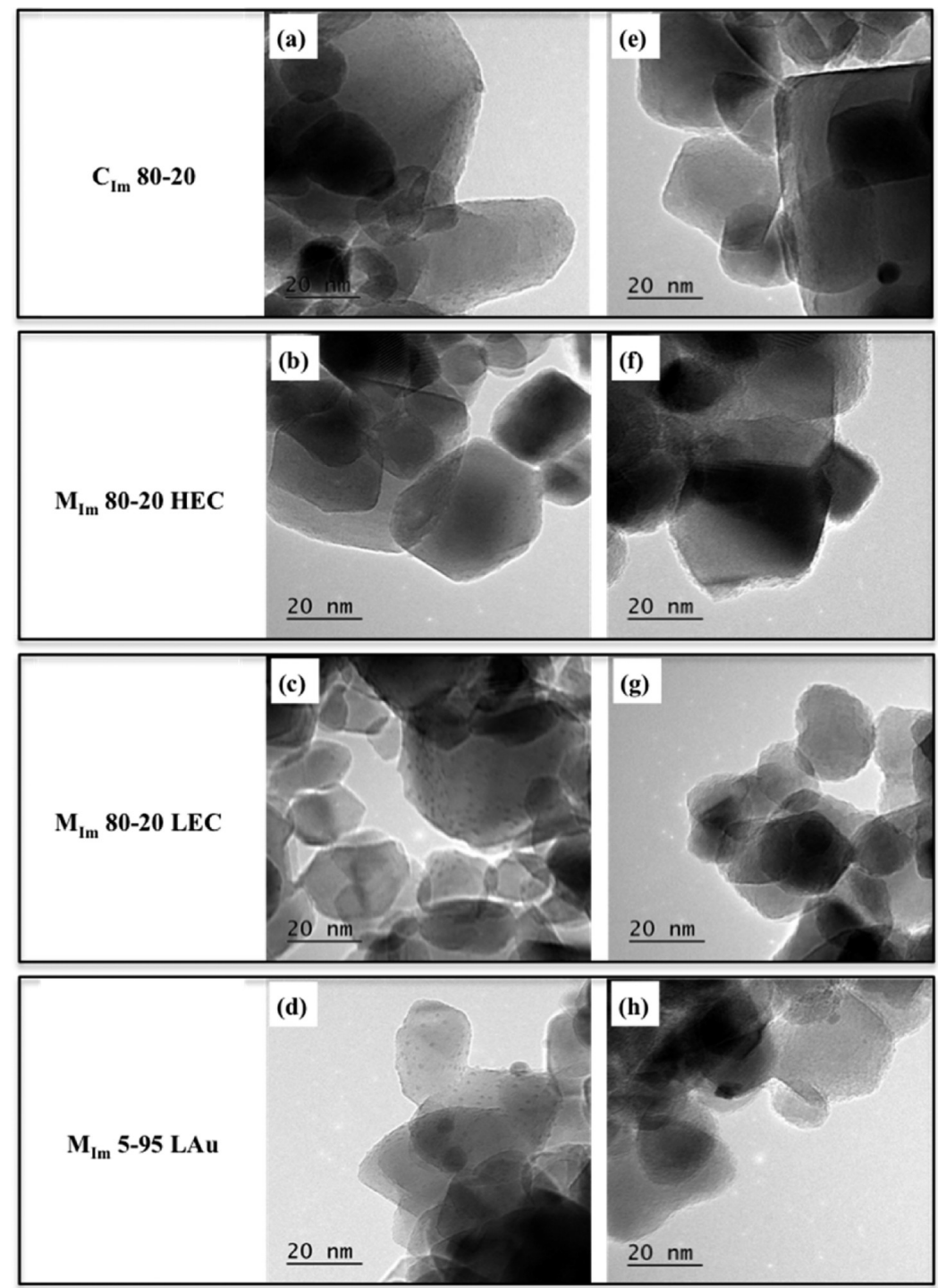

Figure 9. TEM images of $M_{\operatorname{Im}} 80-20 \mathrm{HEC} / \mathrm{LEC} / \mathrm{Lau}$ and $\mathrm{C}_{\mathrm{Im}}$. $(\mathrm{a}-\mathrm{d})$ fresh catalyst and $(\mathrm{e}-\mathrm{h})$ used catalyst.

$1.37 \times 10^{-3} \mathrm{~mol} \mathrm{Cl}^{-}$) was the most stable. $\mathrm{M}_{\mathrm{Im}} 65-35$, the catalyst with relatively low gold and moderate $\mathrm{Cl}^{-}(1.07 \times$ $10^{-3}$ moles of $\mathrm{Cl}^{-}$) was also resistant to deactivation. This indicates that the amount of $\mathrm{Au}$ has an equally prominent effect on stability as the amount of $\mathrm{Cl}^{-}$, and a high chloride content has a detrimental effect only on the catalysts with a substantial $\mathrm{Au}$ amount ( $>65 \%$ Au of total metal).

3.3. Catalyst Characterization. The fresh and used catalyst samples were characterized using HR-STEM coupled with energy dispersive X-ray (EDS) mapping. The three main modes of catalyst deactivation were investigated: (1) adsorption of species (investigated via Raman Spectroscopy and TEM) (2) sintering or agglomeration (via TEM and SEM) and (3) metal leaching or dissolution (via AES of the liquid product mixture). In addition, XPS was carried out on the fresh and used catalyst to determine the presence or absence of residual $\mathrm{Cl}^{-}$.

3.3.1. Catalyst Composition. XPS analysis was carried out on the most unstable catalyst $\mathrm{M}_{\text {Im }}$ HEC 80-20 Au-Pd. The XPS results showed no significant difference in composition between the fresh and used catalyst (Table 2 and Figure 5). XPS also revealed that $\mathrm{Au}$ and $\mathrm{Pd}$ metals were in their metallic states before and after reaction. The XPS analysis was particularly important to confirm the presence or absence of $\mathrm{Cl}^{-}$in the fresh catalyst. The results show no residual $\mathrm{Cl}^{-}$in the fresh or used catalyst, and if present, the $\mathrm{Cl}^{-}$amount is below the XPS detection limits (around 0.1 atom \%).

3.3.2. Metal Leaching into Solution. Solutions of the reaction product mixture for the most unstable catalyst $\left(\mathrm{M}_{\mathrm{Im}}\right.$ 80-20 HEC) were obtained after $2000 \mathrm{~min}$ of reaction analyzed using AES. The solutions were found to have no gold or palladium above the levels that can be detected with AES. For gold and palladium, intensities become differentiated to the background noise at $0.1 \mathrm{ppm}$.

3.3.3. Elemental Analysis. BSE-SEM images of the fresh $\mathrm{M}_{\mathrm{Im}}$ and $\mathrm{C}_{\mathrm{Im}}$ catalysts are presented in Figure 6. Metal particles in the specimen backscatter the high-energy electrons more strongly and therefore appear brighter than the $\mathrm{TiO}_{2}$ support. These metal particles (or clusters of particles, due to their large size) are visible in all the catalysts. Nanoparticles that are 1-2 $\mathrm{nm}$ are not visible at these scales and will therefore be studied using TEM later in this article. The large clusters observed in the SEM images represent a small percentage of the overall number of particles, however, they are observable in larger numbers in the catalysts which had a higher rate of deactivation, $\mathrm{M}_{\mathrm{Im}}$ 80-20 HEC 

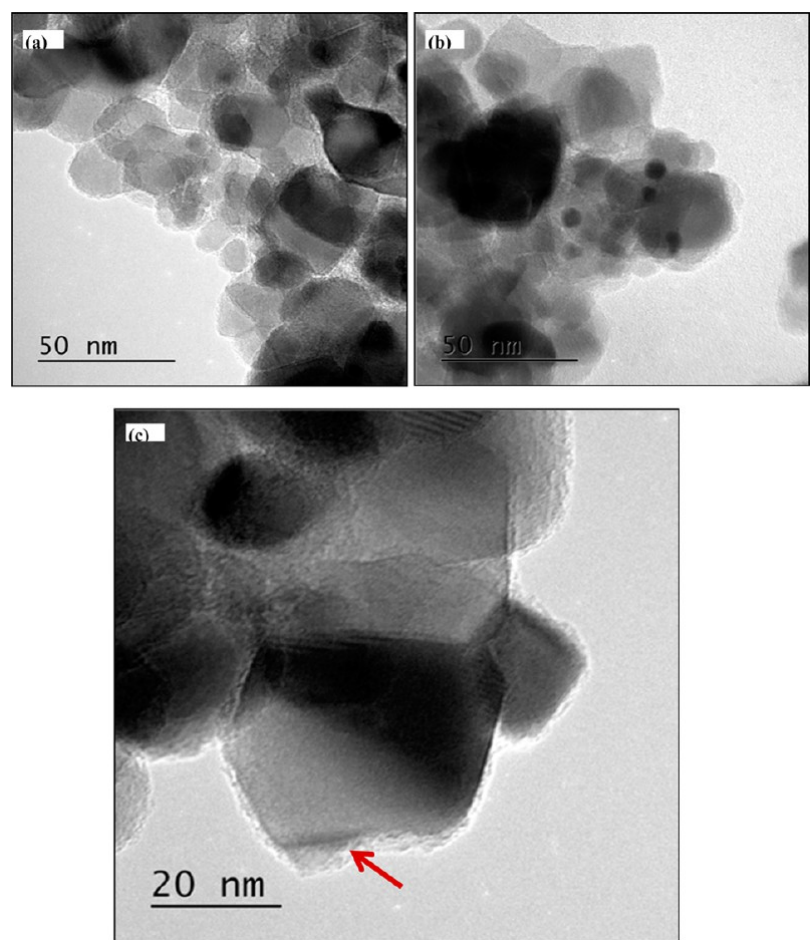

Figure 10. $(a-c)$ TEM images of used $M_{I m}$ 80-20 HEC catalyst showing surface film.

and $\mathrm{M}_{\mathrm{Im}} 80-20$ LEC (deactivation index of 0.75 and 0.13 ), and not observable in the stable $\mathrm{M}_{\mathrm{Im}}$ catalyst: $\mathrm{M}_{\mathrm{Im}}$ 5-95 LAu. However, this is unlikely to have an effect on the catalyst stability as initial particle size is not expected to affect the stability of the catalyst.

To further investigate the bright particles observed with BSE imaging in SEM, the catalysts were analyzed with HR-STEM coupled with EDS to identify the elements constituting these clusters. Electron images were first obtained to locate the clusters within the specimen and an elemental analysis was then carried out on these clusters. The results shown in Figure 7 and Figure 8 confirm that the clusters observed are metal clusters, which are gold-rich when the catalyst is mainly $\mathrm{Au}$ (i.e., in the $\mathrm{M}_{\mathrm{Im}}$ 80-20 HEC) and palladium-rich when the catalyst formulation is mainly $\mathrm{Pd}$ (i.e., in the $\mathrm{M}_{\mathrm{Im}}$ 5-95 LAu). The images shown are representative of the entire catalyst sample (multiple areas were imaged and the results are representative examples of what was observed).

3.3.4. Morphological Changes. All used catalysts were retrieved from the micropacked bed reactor and examined for morphological changes and deposition of species on the catalyst surface. To retrieve the catalyst, acetone was used to flush the reactor and deliver the catalyst into a vial, where it was collected. The catalyst dispersed in the reaction mixture/acetone solution was flushed repeatedly with acetone to dissolve reactant/ products and left to dry in air.

The $\mathrm{C}_{\mathrm{Im}}$ catalyst support morphology was unchanged after the reaction when compared to the fresh catalyst (Figure 9). On the other hand, the $\mathrm{M}_{\mathrm{Im}}$ support morphology did undergo a change, the degree of which depended on the chloride amount used during the synthesis. The $\mathrm{M}_{\mathrm{Im}} 80-20 \mathrm{HEC}$ had the most noticeable morphological change, showing an amorphous carbon coating (Figure 10).

3.3.5. Particle Size. In fresh catalysts, two particle size ranges were observed, with particles in the $1-2 \mathrm{~nm}$ range, as well as $>10 \mathrm{~nm}$.
The average metal particle size was $3.3 \mathrm{~nm}, 0.81 \mathrm{~nm}, 1.25 \mathrm{~nm}$ for $\mathrm{M}_{\mathrm{Im}}$ 80-20 HEC, $\mathrm{M}_{\mathrm{Im}} 80-20 \mathrm{LEC}$, and $\mathrm{M}_{\mathrm{Im}}$ 5-95 LAu, respectively, obtained by averaging 150 particles via TEM (Figure 11). Despite the $M_{I m}$ catalysts having stability in the order $M_{I m}$ 5-95 LAu > $\mathrm{M}_{\mathrm{Im}}$ 80-20 LEC $>\mathrm{M}_{\mathrm{Im}}$ 80-20 HEC, no similar correlation is observed with particle size. Enlarged TEM images from Figure 11 are shown in the Supporting Information (Figure S2-S4).

An interesting observation, however, is that the small $1-2 \mathrm{~nm}$ metal particles could not be observed post-reaction in any of the $\mathrm{M}_{\mathrm{Im}}$ catalysts, despite the AES analysis showing no metal leaching into solution. This suggests that sintering of small metal particles or dissolution followed by redeposition onto larger particles could be the reason for the observed reduction in the catalytic activity. This hypothesis is supported by the appearance of large $>20 \mathrm{~nm}$ agglomerates in the used HEC catalysts (Figure 12a-c). We did not observe these large agglomerates with the LAu catalysts as shown in Figure 12d. For the LEC catalyst, the dark areas featured in the TEM image are most likely a mixture of both agglomerated particles and more than one superimposed layer of the titania support (Figure 12e).

The agglomeration of particles has more influence on catalyst activity in Au-rich catalysts in comparison to those that are Pd-rich, which is due to the stronger influence of particle size on activity in Au-rich catalysts. ${ }^{24}$ A secondary deactivation mechanism may be attributed to the observed morphological changes, appearing in the form of a surface film. To investigate the nature of this surface film, Raman spectroscopy was carried out on the used catalyst.

3.4. Raman Spectroscopy. Raman spectra of the $M_{I m}$ 80-20 HEC catalyst at different locations within the microreactor are shown in Figure 13. The peaks at Raman shifts of 143, 395,517 , and $634 \mathrm{~cm}^{-1}$ are typical peaks of the catalyst support $\mathrm{TiO}_{2}$ (anatase). The metallic $\mathrm{Au}-\mathrm{Pd}$ particles have no intrinsic Raman spectrum. Broad features were observed at $1585 \mathrm{~cm}^{-1}$ ( $G$ band), which are indicative of the presence of carbon species; ${ }^{25}$ these could be deposits of reaction products. The $\mathrm{G}$ band is attributed to graphitic carbon, which arises from the in-plane carbon-carbon stretching vibrations of pairs of $\mathrm{sp}^{2}$ carbons. The presence of $\mathrm{Cl}^{-}$during the catalyst preparation may be affecting the structure of $\mathrm{Au}-\mathrm{Pd}$ particles (i.e., alloy or a core-shell structure) and thus their susceptibility for carbon deposition. A different degree of carbon deposition is found on catalyst particles sampled at different reactor positions, with a higher amount of carbon found toward the end of the reactor. This indicates that the deactivation mechanism is of a series nature, that is, the carbon deposits are formed from the products (or byproducts), and if these are absent in the feed, none can be formed at the entrance of the bed. ${ }^{26}$ Hence, carbon profiles that increase with bed length are obtained. In comparison with work in the literature, carbon species covering the catalyst after reaction have been observed for the liquid phase hydrogenation of furfural over $\mathrm{Cu} / \mathrm{Al}_{2} \mathrm{O}_{3}$ catalyst where the resinification of furfural causes reversible deactivation. ${ }^{27}$

\section{CONCLUSION}

The deactivation behavior of $\mathrm{Au}-\mathrm{Pd}$ catalysts supported on $\mathrm{TiO}_{2}$ was studied during the aerobic oxidation of benzyl alcohol in a micropacked bed reactor. Analysis of the stability with time on stream revealed a catalyst deactivation rate that is dependent on the amount of chloride used in its preparation. This dependence is prominent in catalysts containing $\mathrm{Au}$ amounts in excess of $65 \%$ of the total metal content. The most stable $\mathrm{M}_{\mathrm{Im}}$ catalyst 


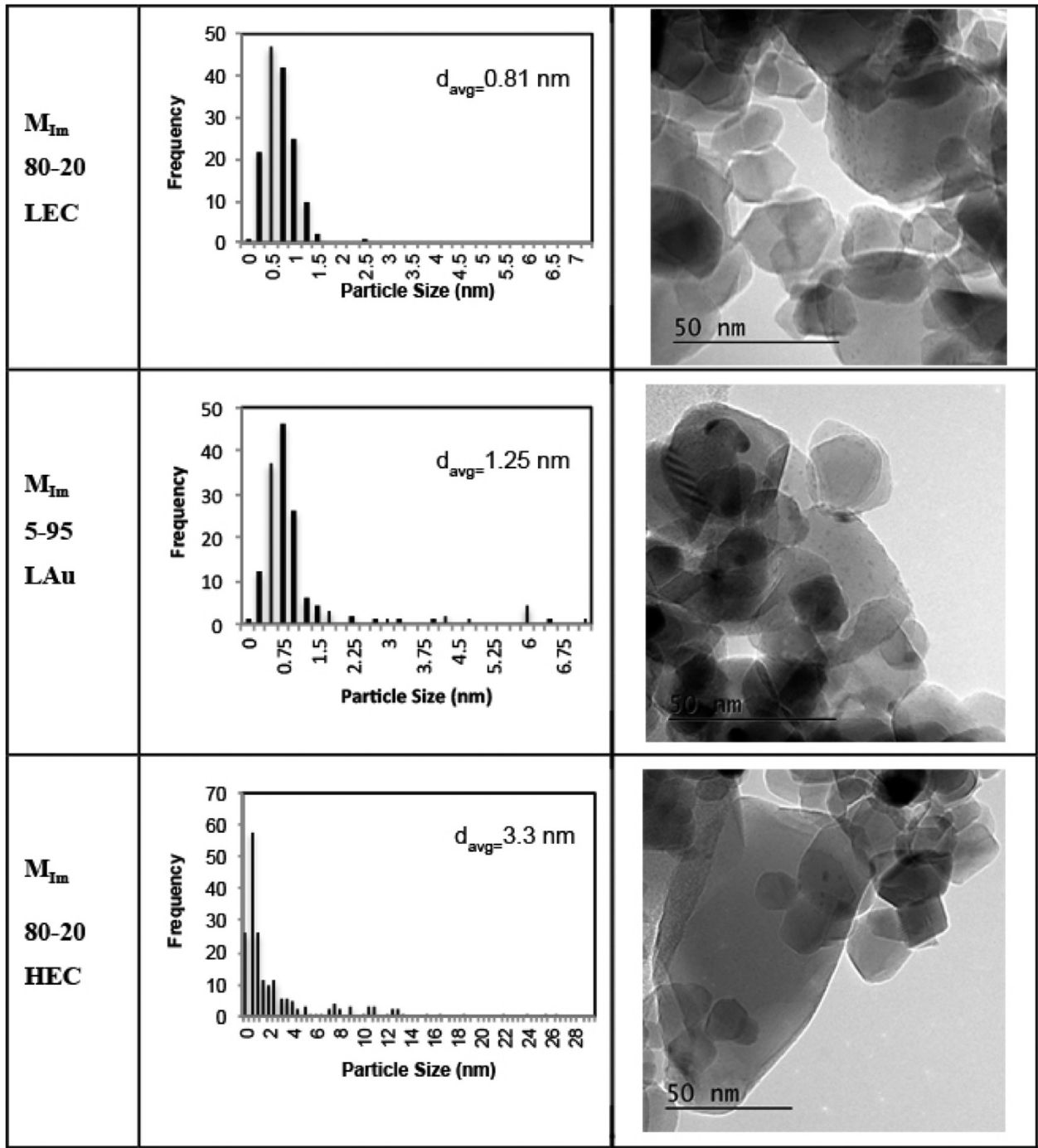

Figure 11. Particle size distributions for the fresh $\mathrm{M}_{\mathrm{Im}}$ catalysts with example images used for the particle count. Enlarged images of the nanoparticles are shown in the Supporting Information.
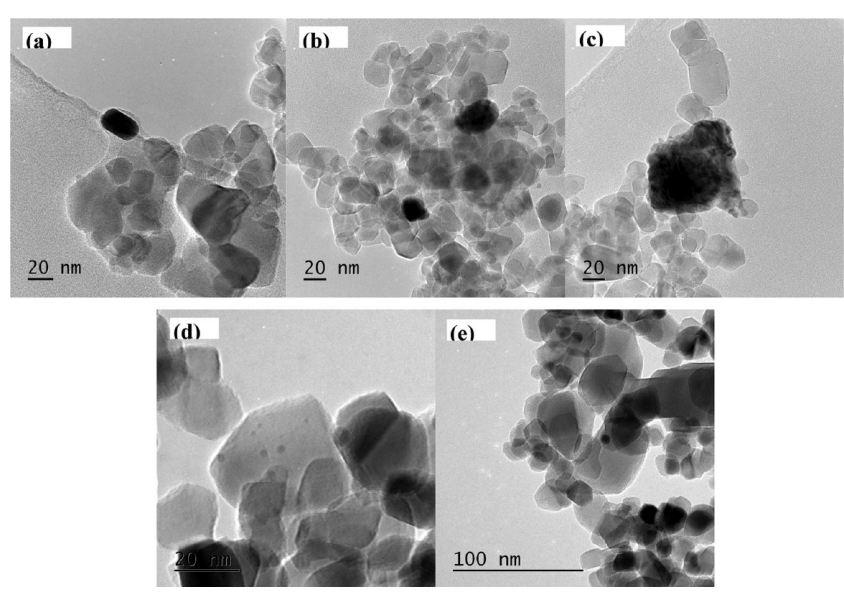

Figure 12. Representative TEM images of $(\mathrm{a}-\mathrm{c}) \mathrm{M}_{\mathrm{Im}} 80-20 \mathrm{HEC}$ (d) $\mathrm{M}_{\mathrm{Im}}$ 5-95 LAu, and (e) $\mathrm{M}_{\mathrm{Im}}$ 80-20 LEC after reaction.

was the $\mathrm{M}_{\mathrm{Im}}$ 5-95 LAu (due to its low gold content) and $\mathrm{M}_{\mathrm{Im}}$ 65-35 (due to its low $\mathrm{Cl}^{-}$in conjunction with moderate $\mathrm{Au}$ ).

HR-STEM EDS examination of the catalyst showed metal nanoparticles that are rich in the metal that is most abundant in

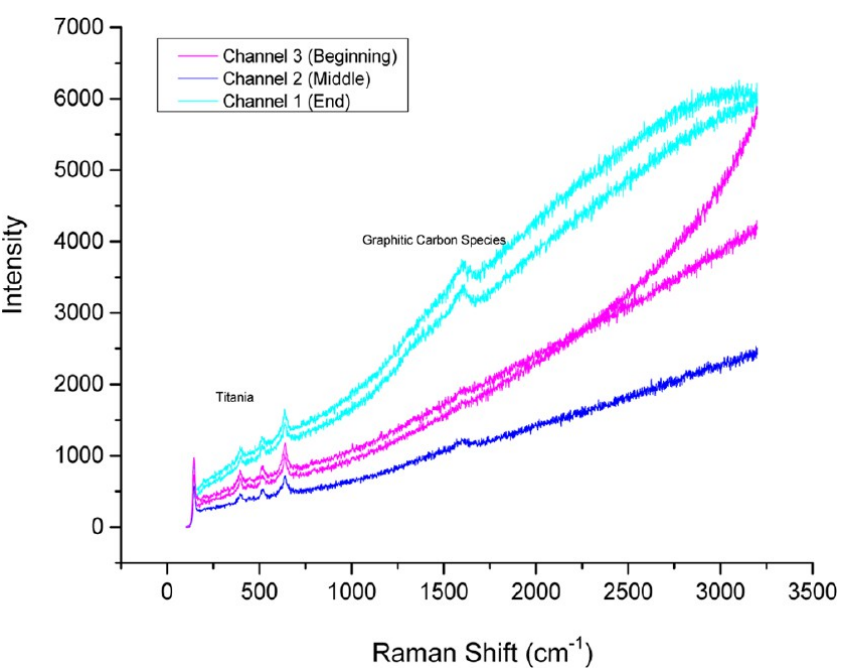

Figure 13. Raman spectra of $M_{\operatorname{Im}} 80-20$ HEC catalyst post-reaction at different locations in the microreactor.

the catalyst formulation. The leaching of small 1-2 nm nanoparticles and agglomeration into larger $>10 \mathrm{~nm}$ particles appears 
to take place during reaction, as evidenced by TEM analysis of the catalyst post-reaction. AES analysis demonstrated that there was no metal leaching into solution, further supporting the agglomeration hypothesis. Although this phenomenon took place in all catalysts studied, the high Au formulations suffered in stability the most, due to the high dependence of Au activity on particle size.

TEM examination of catalysts postreaction also showed an amorphous surface film covering the catalyst surface. This surface film could be poisoning the catalyst surface and blocking access to the active sites-containing metal, forming a secondary deactivation mechanism. This hypothesis is supported by Raman spectroscopy, which revealed the presence of carbon species on the catalyst surface that was dependent on the axial position in the reactor, suggesting that the carbon deposits are formed from reaction products. This deactivation mechanism could be facilitated by the presence of $\mathrm{Cl}^{-}$in the catalyst preparation, possibly through its influence on the morphology of the $\mathrm{Au}-\mathrm{Pd}$ alloy (core-shell or alloy structure). Different alloy morphologies mean that different metals could be exposed on the catalyst surface, which may be more susceptible to deactivation.

\section{ASSOCIATED CONTENT}

\section{S Supporting Information}

The Supporting Information is available free of charge on the ACS Publications website at DOI: 10.1021/acs.iecr.7b01159.

Magnified TEM images showing the 1-2 nm nanoparticles in fresh catalysts; product selectivity graphs with time on stream showing the independence of selectivity on the rate of deactivation (PDF)

\section{AUTHOR INFORMATION}

\section{Corresponding Author}

*E-mail: a.gavriilidis@ucl.ac.uk.

ORCID

David Morgan: 0000-0002-6571-5731

Asterios Gavriilidis: 0000-0003-3508-5043

Notes

The authors declare no competing financial interest.

\section{ACKNOWLEDGMENTS}

Funding from EPSRC for a studentship (N.A.R.) and through Grants $\mathrm{EP} / \mathrm{J} 017833 / 1$ and $\mathrm{EP} / \mathrm{J} 017868 / 1$ is gratefully acknowledged.

\section{REFERENCES}

(1) Hudlicky, M. Oxidation in Organic Chemistry; American Chemical Society: Washington DC, 1990.

(2) Enache, D. I.; Edwards, J. K.; Landon, P.; Solsona-Espriu, B.; Carley, A. F.; Herzing, A. A.; Watanabe, M.; Kiely, C. J.; Knight, D. W.; Hutchings, G. J. Solvent-Free Oxidation of Primary Alcohols to Aldehydes Using Au-Pd/ $\mathrm{TiO}_{2}$ Catalysts. Science 2006, 311, 362-365.

(3) Hou, W. B.; Dehm, N. A.; Scott, R. W. J. Alcohol oxidations in aqueous solutions using $\mathrm{Au}, \mathrm{Pd}$, and bimetallic AuPd nanoparticle catalysts. J. Catal. 2008, 253, 22-27.

(4) Daniel, M. C.; Astruc, D. Gold Nanoparticles: Assembly, Supramolecular Chemistry, Quantum-Size-Related Properties, and Applications toward Biology, Catalysis, and Nanotechnology. Chem. Rev. 2004, 104, 293-346.

(5) Villa, A.; Wang, D.; Su, D. S.; Prati, L. Gold Sols as Catalysts for Glycerol Oxidation: The Role of Stabilizer. ChemCatChem 2009, 1, 510-514.

(6) Sankar, M.; He, Q.; Morad, M.; Pritchard, J.; Freakley, S. J.; Edwards, J. K.; Taylor, S. H.; Morgan, D. J.; Carley, A. F.; Knight, D. W.;
Kiely, C. J.; Hutchings, G. J. Synthesis of Stable Ligand-free GoldPalladium Nanoparticles Using a Simple Excess Anion Method. ACS Nano 2012, 6, 6600-6613.

(7) Morad, M.; Sankar, M.; Cao, E.; Nowicka, E.; Davies, T. E.; Miedziak, P. J.; Morgan, D. J.; Knight, D. W.; Bethell, D.; Gavriilidis, A.; Hutchings, G. J. Solvent-free aerobic oxidation of alcohols using supported gold palladium nanoalloys prepared by a modified impregnation method. Catal. Sci. Technol. 2014, 4, 3120-3128.

(8) Ide, M. S.; Falcone, D. D.; Davis, R. J. On the deactivation of supported platinum catalysts for selective oxidation of alcohols. J. Catal. 2014, 311, 295-305.

(9) Al-Rifai, N.; Cao, E.; Dua, V.; Gavriilidis, A. Microreaction technology aided catalytic process design. Curr. Opin. Chem. Eng. 2013, 2 (3), 338-345.

(10) Sadaba, I.; Lopez Granados, M.; Riisager, A.; Taarning, E. Deactivation of solid catalysts in liquid media: the case of leaching of active sites in biomass conversion reactions. Green Chem. 2015, 17, 4133-4145.

(11) Besson, M.1.; Gallezot, P. Deactivation of metal catalysts in liquid phase organic reactions. Catal. Today 2003, 81, 547-559.

(12) Besson, M.; Gallezot, P. Selective oxidation of alcohols and aldehydes on metal catalysts. Catal. Today 2000, 57, 127-141.

(13) Peri, S. S.; Lund, C. R. F. The Role of Chlorine in Induction Periods During the Oxidation of Methane over $\mathrm{Pd} / \mathrm{SiO}_{2}$. J. Catal. 1995, $152,410-414$.

(14) Marécot, P.; Fakche, A.; Kellali, B.; Mabilon, G.; Prigent, P.; Barbier, J. Propane and propene oxidation over platinum and palladium on alumina: Effects of chloride and water. Appl. Catal., B 1994, 3, 283294.

(15) Marceau, E.; Che, M.; Saint-Just, J.; Tatibouët, J. M. Influence of chlorine ions in $\mathrm{Pt} / \mathrm{A} 12 \mathrm{O} 3$ catalysts for methane total oxidation. Catal. Today 1996, 29, 415-419.

(16) Fuentes, G. A., Gamas, E. D., Towards, A Better Understanding of Sintering Phenomena in Catalysis. In Studies in Surface Science and Catalysis - Catalyst Deactivation; Bartholomew, C. H., Butt, J. B., Eds.; Elsevier: New York, 1991; Vol. 68, pp 637-644.

(17) Albonetti, S., Mazzoni, R., Cavani, F. Homogeneous, Heterogeneous and Nanocatalysis. In Transition Metal Catalysis in Aerobic Alcohol Oxidation. The Royal Society of Chemistry, 2015; Chapter 1, pp 1-39.

(18) Skupien, E.; Berger, R.; Santos, V.; Gascon, J.; Makkee, M.; Kreutzer, M.; Kooyman, P.; Moulijn, J. A.; Kapteijn, F. Inhibition of a Gold-Based Catalyst in Benzyl Alcohol Oxidation: Understanding and Remediation. Catalysts 2014, 4, 89-115.

(19) Cao, E.; Sankar, M.; Firth, S.; Lam, K. F.; Bethell, D.; Knight, D. K.; Hutchings, G. J.; McMillan, P. F.; Gavriilidis, A. Reaction and Raman spectroscopic studies of alcohol oxidation on gold-palladium catalysts in microstructured reactors. Chem. Eng. J. 2011, 167, 734-743.

(20) Meenakshisundaram, S.; Nowicka, E.; Miedziak, P. J.; Brett, G. L.; Jenkins, R. L.; Dimitratos, N.; Taylor, S. H.; Knight, D. W.; Bethell, D.; Hutchings, G. J. Oxidation of alcohols using supported gold and goldpalladium nanoparticles. Faraday Discuss. 2010, 145, 341-356.

(21) Enache, D. I.; Edwards, J. K.; Landon, P.; Solsona-Espriu, B.; Carley, A. F.; Herzing, A. A.; Watanabe, M.; Kiely, C. J.; Knight, D. W.; Hutchings, G. J. Solvent-free oxidation of primary alcohols to aldehydes using $\mathrm{Au}-\mathrm{Pd} / \mathrm{TiO}_{2}$ catalyst. Science 2006, 311, 362-365.

(22) Cao, E.; Sankar, M.; Nowicka, E.; He, Q.; Morad, M.; Miedziak, P. J.; Taylor, S. H.; Knight, D. W.; Bethell, D.; Kiely, C. J.; Gavriilidis, A.; Hutchings, G. J. Selective suppression of disproportionation reaction in solvent-less benzyl alcohol oxidation catalysed by supported Au-Pd nanoparticles. Catal. Today 2013, 203, 146-152.

(23) Sankar, M.; Nowicka, E.; Tiruvalam, R.; He, Q.; Taylor, S. H.; Kiely, C. J.; Bethell, D.; Knight, D. W.; Hutchings, G. J. Controlling the Duality of the Mechanism in Liquid-Phase Oxidation of Benzyl Alcohol Catalysed by Supported Au-Pd Nanoparticles. Chem. - Eur. J. 2011, 17, 6524-6532.

(24) Dimitratos, N.; Lopez-Sanchez, J. L.; Lennon, D.; Porta, F.; Prati, L.; Villa, A. Effect of Particle Size on Monometallic and Bimetallic $(\mathrm{Au}, \mathrm{Pd}) / \mathrm{C}$ on the Liquid Phase Oxidation of Glycerol. Catal. Lett. 2006, 108, 147. 
(25) Liu, D.; Quek, X. Y.; Cheo, W. N. E.; Lau, R.; Borgna, A.; Yang, Y. MCM-41 supported nickel-based bimetallic catalysts with superior stability during carbon dioxide reforming of methane: Effect of strong metal-support interaction. J. Catal. 2009, 266, 380-390.

(26) Anderson, J. R., Boudart, M. Catalysis: Science and Technology; Springer-Verlag: Tokyo, 1984.

(27) O'Neill, B.; Sener, C.; Jackson, D.; Kuech, T.; Dumesic, J. Control of Thickness and Chemical Properties of Atomic Layer Deposition Overcoats for Stabilizing $\mathrm{Cu} / \gamma-\mathrm{Al}_{2} \mathrm{O}_{3}$ Catalysts. ChemSusChem 2014, 7, 3247-3251. 